\title{
Genotypes of Cryptococcus neoformans and Cryptococcus gattii as agents of endemic cryptococcosis in Teresina, Piauí (northeastern Brazil)
}

\author{
Liline Maria Soares Martins ${ }^{1 /+}$, Bodo Wanke², Márcia dos Santos Lazéra², Luciana Trilles², \\ Gláucia Gonçalves Barbosa ${ }^{2}$, Regina Célia Lima de Macedo $^{2}$, Maria do Amparo Salmito Cavalcanti ${ }^{3}$, \\ Kelsen Dantas Eulálio ${ }^{3}$, José Adail Fonseca de Castro', Adalberto Socorro da Silva', \\ Fernando Ferraz do Nascimento ${ }^{1}$, Viviane Alves Gouveia ${ }^{4}$, Semiramis Jamil Hadad do Monte ${ }^{1}$
}

\begin{abstract}
${ }^{1}$ Laboratório de Imunogenética e Biologia Molecular, Universidade Federal do Piauí, Campus Ministro Petrônio Portella Bloco SG-16, 64049-550 Teresina, PI, Brasil 2Laboratório de Micologia, Instituto de Pesquisa Clínica Evandro Chagas-Fiocruz, Rio de Janeiro, RJ, Brasil ${ }^{3}$ Instituto de Doenças Tropicais Natan Portella, Teresina, PI, Brasil ${ }^{4}$ Instituto de Ciências Biológicas, Laboratório de Microbiologia, Universidade Federal de Minas Gerais, Belo Horizonte, MG, Brasil
\end{abstract}

Throughout Brazil, Cryptococcus neoformans is the cause of cryptococcosis, whereas Cryptococcus gattii is endemic to the northern and northeastern states. In this study, the molecular types of 63 cryptococcal isolates recovered from the cerebrospinal fluid of meningitis patients diagnosed between 2008-2010 in Teresina, Piaui, Brazil, were analysed. Out of the 63 patients, 37 (58.7\%) were human immunodeficiency virus (HIV)-positive and 26 (41.3\%) were HIV-negative. URA5-restriction fragment length polymorphism analysis identified $37 / 63$ (58.7\%) isolates as the C. neoformans VNI genotype, predominantly in HIV-positive patients (32/37, 86.5\%), and 24/63 (38.1\%) as the C. gattii VGII genotype, mostly in HIV-negative patients (21/26, 80.8\%). The occurrence of C. gattii VGII in six apparently healthy children and in seven adolescents/young adults in this region reaffirms the endemic occurrence of $\mathrm{C}$. gattii VGII-induced primary cryptococcosis and early cryptococcal infection. Lethality occurred in 18/37 (48.6\%) of the HIV-positive subjects and in 13/26 (50\%) of the HIV-negative patients. Our results provide new information on the molecular epidemiology of $\mathrm{C}$. neoformans and $\mathrm{C}$. gattii in Brazilian endemic areas.

Key words: Cryptococcus gattii - Cryptococcus neoformans - genotypes - endemic mycoses - children - immunocompetent host

Cryptococcosis is a global and invasive systemic mycosis caused by Cryptococcus neoformans (genotypes VNI, VNII, VNIII and VNIV) and Cryptococcus gattii (genotypes VGI, VGII, VGIII and VGIV) (Meyer et al. 2003). The infection is acquired by inhalation of viable propagules present in the environment. It primarily colonizes the lung but often spreads to other organs, especially the central nervous system (CNS), causing meningoencephalitis and cryptococcomas (Galanis \& MacDougall 2010).

Globally, cryptococcosis by $C$. neoformans is a major cause of morbidity and mortality in immunocompromised individuals [e.g., in those with acquired immune deficiency syndrome (AIDS) or lymphoproliferative disorders and in those undergoing corticosteroid therapy and following organ transplantation]. In contrast, C. gattii infections prevail in regions with tropical and subtropical climates, predominantly affecting immuno-

Financial support: Post Graduate Program of Biotechnology/RENORBIO, Research and Technological Development Program/UFPI (PIPDT 20091.013 - IPEC-FIOCRUZ)

+ Corresponding author: liline-martins@uol.com.br

Received 22 March 2011

Accepted 16 August 2011 competent hosts (Lazera et al. 2005, Jobbins et al. 2010). Moreover, C. gattii has been linked to human and animal outbreaks and has been isolated in countries of temperate climate, demonstrating that the fungus can adapt to new or formerly unknown environments (Kidd et al. 2004, Byrnes \& Heitman 2009, Dixit et al. 2009).

In Brazil, cryptococcosis caused by $C$. neoformans occurs in all regions and it often causes systemic mycosis in AIDS patients and is the third leading cause of opportunistic CNS infection in these patients (Junior et al. 2006). Of the more than 215,000 registered AIDS patients in Brazil from 1980-2002, 6\% were diagnosed with cryptococcosis (Nucci et al. 2010). However, $C$. gattii acts predominantly as a primary pathogen, attacking immunocompetent hosts, including children and young adults in North and Northeast, and is therefore considered endemic to the states of Amazonas (AM), Pará (PA), Roraima, Piauí (PI), Pernambuco and Bahia (Trilles et al. 2008). The southern and southeastern regions show sporadic infections by $C$. gattii (Severo et al. 2009, Mora et al. 2010, Pinto Junior et al. 2010). In PI, previous studies have shown that cryptococcosis caused by $C$. gattii is strongly associated with human immunodeficiency virus (HIV)-negative patients, afflicting a significant portion of children and young adults (Cavalcanti 1995, Martins 2003).

Because cryptococcosis is considered to be an opportunistic infection instead of a disease that requires reporting, there is a lack of epidemiologic data, labora- 
tory resources and therapeutic options, which together complicate the management of severe cryptococcosis infections. Nevertheless, with inexpensive diagnostic tests [e.g., polymerase chain reaction (PCR) of the cerebral spinal fluid], a hightened awareness and a pragmatic approach to antifungal therapy, good therapeutic outcomes can be achieved. Here, we report on the identification of the molecular pattern of the Cryptococcus species that caused meningitis in patients in Teresina, which is the capital of the northeastern state of PI, Brazil, providing a quick tool for diagnosis.

\section{PATIENTS, MATERIALS AND METHODS}

Patients - A total of 63 patients diagnosed with cryptococcal meningitis were analysed from January 2008-July 2010 at Natan Portella Institute of Tropical Diseases, the main reference centre for infectious diseases in PI. The study was approved by the Ethics Committee for Research of the State University of Piauí under protocol 079/2008.

Epidemiological data - The epidemiological, clinical and laboratory information from each patient were obtained from medical records and transferred to an epidemiological database. After hospital discharge, there was no clinical follow-up of the patients. The variables selected for this study were age, geographical location (e.g., rural versus urban) and host factors. Host factors were analysed according to the immunological status of the patient, which was classified as immunocompetent, HIV-negative or HIV-positive. The overall death rate was calculated using the number of deaths divided by the total number of patients diagnosed with cryptococcal meningitis. This concept was applied separately for HIV-positive and negative patients. Because many patients were from another state and arrived with a diagnosis of meningitis, we assumed that their original location was the possible source of infection.

Identification of Cryptococcus isolates - One Cryptococcus isolate was analysed per patient. The isolates were plated on niger seed agar (NSA) medium, transferred to $15 \%$ glycerol and stored at $-20^{\circ} \mathrm{C}$. For the identification of pathogenic Cryptococcus species, isolates were subjected to morphological and physiological tests, including the production of phenol oxidase on NSA medium, sensitivity to cycloheximide, carbon and nitrogen assimilation (Vitek ICB, bioMérieux, Durham, USA) and growth on canavanine-glycine-bromothymol blue medium.

Reference strains - The following set of standard laboratory strains representing each molecular type was used as controls in the URA5-restriction fragment length polymorphism (URA5-RFLP) analysis: WM 148 (serotype A, VNI), WM 626 (sSerotype A, VNII), WM 628 (serotype AD, VNIII), WM 629 (serotype D, VNIV), WM 179 (serotype $\mathrm{B}, \mathrm{VGI}$ ), WM 178 (serotype B, VGII), WM 161 (serotype B, VGIII) and WM 779 (serotype C, VGIV).

DNA extraction - High molecular weight DNA was obtained as described by Ferrer et al. (2001) with some modifications. The isolates were grown in Sabouraud dextrose agar at $37^{\circ} \mathrm{C}$ for $48 \mathrm{~h}$. Then, approximately $150 \mathrm{mg}$ of the cell pellet was transferred to a microtube and frozen at $-20^{\circ} \mathrm{C}$ overnight. Five hundred microlitres of lysis solution [1.5\% $\mathrm{NaCl}, 0.5 \%$ sodium dodecyl sulfate, $0.25 \mathrm{M}$ ethylenediamine tetraacetic acid (EDTA) $\mathrm{pH} 8.0$ and Tris- $\mathrm{HCl} 10 \mathrm{mM}, \mathrm{pH} 7.5$ ] and $5 \mu \mathrm{L}$ of 2-mercapto-ethanol (Sigma Aldrich, USA) were added to the microtube. The tube was incubated at room temperature and vortexed for $5 \mathrm{~min}$ before being placed in a $65^{\circ} \mathrm{C}$ dry bath with occasional stirring. The lysate was centrifuged for $15 \mathrm{~min}$ at $14,100 \mathrm{~g}$ and the aqueous phase was transferred to a new tube. Five hundred microlitres of phenol-chloroform-isoamyl alcohol (25:24:1, v:v:v) was added and the sample was stirred for 4 min to obtain a homogenous suspension and then centrifuged for $15 \mathrm{~min}$ at $14,100 \mathrm{~g}$. To the DNA precipitate, cold isopropanol (1:1) was added, mixed lightly and incubated at $-20^{\circ} \mathrm{C}$ overnight. The DNA pellet was washed with $70 \%$ ethanol, air-dried and suspended in $500 \mu \mathrm{L}$ of TE (10 mM Tris-HCL, pH 7.5, 0.5 M EDTA, pH 8.0) containing $50 \mu \mathrm{g} / \mathrm{mL}$ RNAse A (Invitrogen, USA), incubated at $37^{\circ} \mathrm{C}$ for $40 \mathrm{~min}$ and stored at $-20^{\circ} \mathrm{C}$. The extracted DNA was analysed using a $1 \%$ agarose gel with visualisation under ultraviolet light. The DNA concentration was determined using a spectrophotometer at 260/280 nm.

Establishment of the genotype by URA5-RFLP analysis - The reaction for amplification of the URA5 gene was carried out in a final volume of $30 \mu \mathrm{L}$. Each reaction contained $50 \mathrm{ng}$ genomic DNA, 1 x PCR buffer (20 mM Tris-HCL, pH 7.5, $100 \mathrm{mM} \mathrm{NaCl}, 0.1 \mathrm{mM}$ EDTA, $2 \mathrm{mM}$ DCT, $50 \%$ glycerol, $0.1 \%$ Tween-20), $0.2 \mathrm{mM}$ each of dATP, dCTP, dGTP and dTTP (Roche Diagnostics $\mathrm{GmbH}$ ), $2 \mathrm{mM}$ magnesium chloride, 2.5 units (U) of Taq DNA polymerase (Bioline) and $25 \mathrm{ng}$ of each primer: URA5 (5' ATGTCCTCCCAAGCCCTCGACTCCG 3') and SJ01 (5' TTAAGACCTCTGAACACCGTACTC 3'). The PCR was performed using the following parameters: $94^{\circ} \mathrm{C}$ for $5 \mathrm{~min}$ followed by 35 cycles of $94^{\circ} \mathrm{C}$ for $45 \mathrm{~s}, 63^{\circ} \mathrm{C}$ for $1 \mathrm{~min}, 72^{\circ} \mathrm{C}$ for $2 \mathrm{~min}$ and an extension cycle of $72^{\circ} \mathrm{C}$ for $10 \mathrm{~min}$. The PCR product was double digested with Sau $96 \mathrm{I}(10 \mathrm{U} / \mu \mathrm{L})$ and HhaI $(20 \mathrm{U} / \mu \mathrm{L})$ for $3 \mathrm{~h}$. The DNA fragments were separated by electrophoresis in a 3\% agarose gel and stained with ethidium bromide. RFLP standards were visually assessed by comparison with the enzymatic digestion profile obtained from the reference strains described above.

Statistical analysis - The data from patients and the isolated fungi were analysed with the chi-square test using SPSS software, version 10.0. $\mathrm{p}$ values of less than 0.05 were considered significant.

\section{RESULTS}

Sixty-three patients diagnosed with mycological cryptococcal meningitis were studied. The patients were predominantly male $(38 / 63,60.3 \%)$ and came from rural or urban areas of PI $(38 / 63,60.3 \%)$, Maranhão (MA) $(23 / 63,36.5 \%)$ and PA $(2 / 63,3.2 \%)$. The majority of patients were HIV-positive (37/63, 58.7\%) and $26(41.3 \%)$ were HIV-negative. The ages ranged from seven-72 years old, with means of 34.1 years in HIV-positive and 28.1 years in HIV-negative patients. All HIV-positive patients were older than 23 years old and 13 out of the $26(50 \%)$ HIV-negative patients were younger than 19 years old. 
Gel electrophoresis was used to identify the molecular types of $C$. neoformans and $C$. gattii of the 63 clinical isolates (Figure). The C. neoformans VNI genotype was the most frequent molecular type $(37 / 63,58.7 \%)$, followed by the $C$. gattii VGII genotype $(24 / 63,38.1 \%)$. In the HIV-positive group, 32 out of $37(86.5 \%)$ cases were caused by $C$. neoformans VNI, followed by $C$. gattii VGII (3/37, 8.1\%), C. gattii VGI (1/37, 2.7\%) and C. neoformans VNII (1/37, 2.7\%). In the HIV-negative group, 21 out of $26(80.8 \%)$ cases were caused by $C$. gattii VGII, followed by $C$. neoformans VNI (5/26, 19.2\%). The mean age of the patients with $C$. neoformans VNI was 20 years old, which was not significantly different from those infected by $C$. gattii VGII (28.6 years old) ( $p$ $=0.567)$. However, the age range was significantly wider for $C$. gattii $(\mathrm{p}<0.001)$, which was found in children and adults who were predominantly from rural areas, while C. neoformans occurred only in adults living predominantly in urban areas $(31 / 61 ; \mathrm{p}<0.002)$.

Overall, death occurred in $49.2 \%$ of the cases, consisting of 18/37 (48.6\%) HIV-positive patients and 13/26 $(50 \%) \mathrm{HIV}$-negative patients. This number was significantly higher for patients infected by the $C$. neoformans VNI genotype, with an almost two-fold greater risk of death than those infected with the C. gattii VGII genotype (odds ratio $=1.875)$.

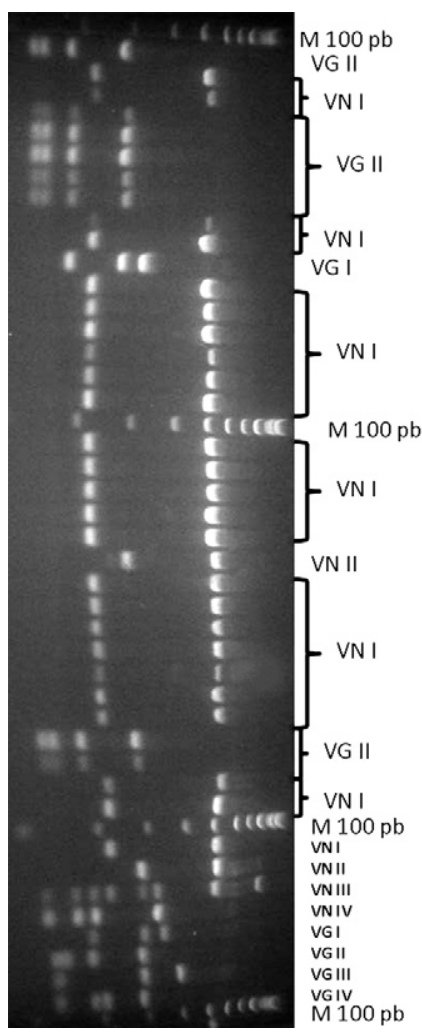

URA5-restriction fragment length polymorphism analyses obtained after double digestion with the enzymes Sau96I (10 U/ $\mu \mathrm{L})$ and HhaI (20 U/ $\mu \mathrm{L}$ ) representing the VNI and VNII (Cryptococcus neoformans), the VGI and VGII (Cryptococcus gattii) and standard genotypes. M: 100 bp DNA ladder (Gibco - BRL, USA).
Cryptococcal meningitis caused by $C$. gattii VGII occurred in six apparently healthy children (up to 12 years old) and in seven adolescents/young adults aged 13-19; all were HIV-negative and $38.4 \%(5 / 13)$ of these patients died.

Our analysis showed that $C$. neoformans VNI predominated in HIV-positive patients, while $C$. gattii VGII predominated in HIV-negative patients $(21 / 26,80.8 \%$; $p$ $<0.001)$. Only $3 / 37(8.1 \%)$ of the HIV-positive cases were caused by $C$. gattii VGII, whereas $5 / 21$ (23.8\%) of the HIV-negative cases were caused by $C$. neoformans VNI. Table summarizes the distribution of the molecular types according to patient data, HIV infection and outcome.

\section{DISCUSSION}

The epidemiology of fungal infections caused by pathogenic Cryptococcus species has been extensively studied worldwide. Unfortunately, few molecular epidemiological studies have been performed in Brazil and the absence of an efficient reporting system restricts the understanding of the clinical and epidemiological data. Another factor that restricts the understanding of the epidemiology of these infections is diagnosis, which is especially important in determining the disease. The tools used to identify these pathogenic yeasts have limitations that make a final diagnosis difficult. However, more recent molecular methods have allowed amplification of specific gene sequences that can be used to detect C. neoformans and C. gattii from clinical and environmental samples. These sequences can be used for identification and genotyping and for studying the population genetics. Here, we used the URA5-RFLP genotyping methodology to determine the molecular types of cryptococcosis. As it is not a disease of compulsory notification in Brazil, an actual estimate of its incidence and prevalence has been limited. We showed that the C. neoformans VNI genotype has a higher occurrence mainly in HIV-positive adults from urban areas and that it had a 1.8-fold higher risk of death when compared to the $C$. gattii VGII genotype. Importantly, $C$. gattii, the second most prevalent species causing CNS cryptococcosis, was found in a high percentage of HIV-negative children and young adults, who were mostly living in rural areas. These results are in agreement with the epidemiological findings in the literature for pathogenic Cryptococcus species worldwide. Previous studies attest that C. neoformans VNI is strongly associated with AIDS throughout Brazil with a higher incidence in the South and Southeast. This result can be explained by the fact that these Regions include the largest cities in the country, where anthropic actions are more evident (Horta et al. 2002, Nishikawa et al. 2003, Matsumoto et al. 2007, Trilles et al. 2008, Mora et al. 2010). Moreover, the ease of obtaining environmental isolates of $C$. neoformans VNI in urban areas of the South and Southeast Brazil strongly suggest that immunocompromised hosts living in these areas may be continuously exposed to inhalation of viable propagules of this fungus in their everyday life (Igreja et al. 2004). On the other hand, cryptococcosis caused by $C$. gattii VGII occurs sporadically in these regions, mostly detected as isolated cases coming from the northern and northeastern regions (Severo et al. 2009). 
TABLE

Distribution of molecular types of Cryptococcus neoformans and Cryptococcus gattii according to gender, age, human immunodeficiency virus (HIV) infection, state, type of dwelling and outcome of 63 patients with cryptococcal meningitis from the states of Piauí, Maranhão and Pará, Brazil (January 2008-July 2010)

\begin{tabular}{|c|c|c|c|c|c|c|c|}
\hline Strain & Gender & Age & HIV & State of residence & Type of dwelling & Molecular type & Outcome \\
\hline 2 & $\mathrm{~F}$ & 27 & + & Piauí & Urban & VNI & Death \\
\hline 3 & M & 49 & + & Piauí & Urban & VNI & Death \\
\hline 9 & $\mathrm{~F}$ & 28 & + & Maranhão & Rural & VNI & Death \\
\hline 11 & M & 57 & + & Maranhão & Rural & VNI & Cured \\
\hline 12 & M & 42 & + & Piauí & Urban & VNI & Death \\
\hline 13 & $\mathrm{~F}$ & 27 & + & Maranhão & Rural & VNI & Cured \\
\hline 14 & M & 26 & + & Maranhão & Urban & VNI & Cured \\
\hline 15 & M & 45 & + & Piauí & Urban & VNI & Death \\
\hline 16 & M & 28 & - & Maranhão & Urban & VNI & Death \\
\hline 17 & $\mathrm{~F}$ & 24 & + & Piauí & Rural & VNI & Death \\
\hline 18 & M & 28 & - & Pará & Urban & VNI & Death \\
\hline 19 & M & 42 & - & Piauí & Rural & VNI & Death \\
\hline 20 & M & 36 & + & Maranhão & Urban & VNI & Cured \\
\hline 21 & $\mathrm{~F}$ & 24 & + & Maranhão & Urban & VNI & Death \\
\hline 23 & M & 53 & + & Piauí & Urban & VNI & Death \\
\hline 24 & M & 36 & + & Piauí & Urban & VNI & Death \\
\hline 25 & $\mathrm{~F}$ & 21 & + & Piauí & Urban & VNI & Cured \\
\hline 26 & $\mathrm{~F}$ & 26 & + & Maranhão & Urban & VNI & Death \\
\hline 27 & M & 29 & + & Piauí & Urban & VNI & Death \\
\hline 28 & $\mathrm{~F}$ & 34 & + & Maranhão & Urban & VNI & Cured \\
\hline 31 & $\mathrm{~F}$ & 30 & + & Piauí & Urban & VNI & Cured \\
\hline 32 & M & 25 & + & Piauí & Urban & VNI & Cured \\
\hline 33 & M & 24 & + & Piauí & Urban & VNI & Cured \\
\hline 38 & M & 36 & + & Maranhão & Urban & VNI & Cured \\
\hline 40 & $\mathrm{~F}$ & 31 & + & Maranhão & Urban & VNI & Cured \\
\hline 41 & $\mathrm{~F}$ & 24 & + & Piauí & Urban & VNI & Death \\
\hline 43 & M & 29 & + & Piauí & Urban & VNI & Cured \\
\hline 44 & M & 32 & + & Maranhão & Urban & VNI & Death \\
\hline 45 & $\mathrm{~F}$ & 25 & - & Piauí & Urban & VNI & Death \\
\hline 48 & M & 41 & + & Piauí & Urban & VNI & Cured \\
\hline 51 & M & 32 & + & Piauí & Urban & VNI & Cured \\
\hline 53 & M & 26 & + & Maranhão & Urban & VNI & Death \\
\hline 54 & $\mathrm{~F}$ & 43 & + & Piauí & Urban & VNI & Cured \\
\hline 55 & M & 34 & + & Piauí & Rural & VNI & Death \\
\hline 56 & M & 38 & + & Piauí & Urban & VNI & Cured \\
\hline 62 & $\mathrm{~F}$ & 44 & - & Maranhão & Rural & VNI & Cured \\
\hline 63 & M & 28 & + & Piauí & Urban & VNI & Death \\
\hline 4 & M & 16 & - & Maranhão & Rural & VGII & Cured \\
\hline 5 & $\mathrm{~F}$ & 7 & - & Piauí & Urban & VGII & Cured \\
\hline 6 & M & 31 & + & Piauí & Rural & VGII & Cured \\
\hline 7 & $\mathrm{~F}$ & 19 & - & Maranhão & Urban & VGII & Cured \\
\hline 8 & $\mathrm{~F}$ & 15 & - & Maranhão & Rural & VGII & Death \\
\hline 1 & M & 8 & - & Piauí & Urban & VGII & Cured \\
\hline 29 & M & 67 & - & Piauí & Urban & VGII & Death \\
\hline 30 & M & 44 & - & Piauí & Rural & VGII & Death \\
\hline 34 & $\mathrm{~F}$ & 49 & - & Piauí & Urban & VGII & Cured \\
\hline 35 & $\mathrm{~F}$ & 11 & - & Piauí & Urban & VGII & Death \\
\hline 36 & $\mathrm{~F}$ & 37 & - & Maranhão & Rural & VGII & Cured \\
\hline 37 & M & 31 & + & Maranhão & Rural & VGII & Death \\
\hline 57 & $\mathrm{~F}$ & 35 & - & Piauí & Urban & VGII & Death \\
\hline 58 & $\mathrm{M}$ & 14 & - & Maranhão & Rural & VGII & Death \\
\hline 59 & $\mathrm{~F}$ & 8 & - & Piauí & Rural & VGII & Death \\
\hline 60 & $\mathrm{M}$ & 13 & - & Pará & Rural & VGII & Cured \\
\hline 61 & $\mathrm{~F}$ & 7 & - & Maranhão & Rural & VGII & Cured \\
\hline 49 & M & 7 & - & Piauí & Rural & VGII & Death \\
\hline
\end{tabular}




\begin{tabular}{lccccccc}
\hline Strain & Gender & Age & HIV & State of residence & Type of dwelling & Molecular type & Outcome \\
\hline 50 & F & 19 & - & Piauí & Urban & VGII & Cured \\
39 & M & 44 & - & Maranhão & Urban & VGII & Cured \\
42 & M & 69 & + & Piauí & Urban & VGII & Cured \\
46 & M & 72 & - & Piauí & Rural & VGII & Cured \\
47 & M & 14 & - & Maranhão & Rural & VGII & Death \\
52 & F & 58 & - & Piauí & Urban & VGII & Cured \\
10 & M & 38 & + & Piauí & Urban & VGI & Death \\
22 & M & 37 & + & Piauí & Urban & VNII & Cured \\
\hline
\end{tabular}

F: female; M: male; +: positive; -: negative.

However, autochthonous cases of C. gattii VGII meningoencephalitis in these regions may also be expected to occur, as was recently reported in a child from Rio de Janeiro (RJ) (Pinto Junior et al. 2010). The discovery of $C$. gattii in North America, coming from the recent outbreak in Canada, suggests that tree and lumber exportation, air currents, water currents and biotic sources such as birds, insects and other animals (Springer \& Chaturvedi 2010) may act as vectors for the spreading of the disease to other regions of the world, far removed from its original endemic region.

In PI, the species $C$. neoformans and $C$. gattii have previously been isolated from the hollows of native trees, with both species occasionally sharing the same hollow. Therefore, this region of Brazil has the epidemiological conditions that may allow both species to cause cryptococcosis in humans (Cavalcanti 1995, Trilles et al. 2003).

A series of cases point to the high prevalence of $C$. neoformans VNI as the agent of cryptococcosis reported in Rio Grande do Sul (82.9\%), São Paulo (95.7\%), RJ $(82.9 \%)$, Minas Gerais $(93.82 \%)$, PA $(85.7 \%)$ and Goiás (96.7\%) (Casali et al. 2003, Igreja et al. 2004, Santos et al. 2008, Souza et al. 2009, Mora et al. 2010).

In our study, the occurrence of cryptococcal meningitis caused by $C$. gattii was high among children and young adults (not older than 20 years) $(13 / 63,19.9 \%)$. This result was similar to studies from 1995-2003 in this same region (Martins 2003), as well as in AM and PA (Santos 2000, Santos et al. 2008). In all of these studies, it is worth noting that none of the children showed signs of pulmonary compromise at the time of their diagnosis with cryptococcal meningitis. Therefore, with pulmonary infections overlooked by physicians, the diagnosis of the mycosis usually occurs when the infection has already spread to the CNS, which certainly aggravates the prognosis.

Epidemiological studies of $C$. gattii infections in British Columbia, Canada (1999-2007), reported by Galanis and MacDougall (2010), showed that out of the 218 cases, $76.6 \%$ were diagnosed with only pulmonary involvement with a low mortality rate $(8.7 \%)$. In a study of nine nonHIV children in Taiwan, all survived and only one became blind (Huang et al. 2010). In the present study, 34.7\% of the $C$. gattii patients died, suggesting that the diagnosis was too late as the fungus had already infected the CNS. Besides, delay in making a proper diagnosis is also aggravated due to the large distances to reach a mycological diagnosis and specific treatment at Natan Portella Institute of Tropical Diseases. Although C. neoformans VNI has an approximately two-fold higher risk of death, it is necessary to consider that this finding may be strongly correlated with the HIV immunocompetence condition because it is the main infectious agent in this group of patients.

Another interesting finding of our study was the identification in one case, as this is a very rare genotype in Brazil. Santos et al. (2008) also reported a case of $C$. gattii VGI in PA. The VGI genotype has been frequently isolated in Canada and the Netherlands (Springer \& Chaturvedi 2010).

Until recently, $C$. gattii was not well studied because infection by this microorganism represented only $1 \%$ of the cryptococcosis cases worldwide (Hansong \& Robin 2009). Even in areas where C. gattii is endemic, such as Australia, the infection rate is 0.94 cases per million residents per year (Chen et al. 2000, Sorrell 2001). Nevertheless, the recent cryptococcosis epidemic caused by $C$. gattii has stimulated more studies on this species. This epidemic was initially observed in 1999 in Vancouver Island, Canada. From 2002-2006, the annual average incidence of cryptococcosis in the affected region was 6.5 cases per million in British Columbia and 27.9 cases per million in Vancouver Island (DeBess et al. 2010, Galanis \& MacDougall 2010, Springer \& Chaturvedi 2010). The increase in the epidemiology of $C$. gattii is likely a consequence of alterations in the ecology and biology of this fungus, including its increasing ability to cause life-threatening disease. The colonisation of environments in Vancouver Island and possibly in other neighbouring regions indicates that $C$. gattii is capable of adapting to new environmental conditions (Dixit et al. 2009). The temperate climate of Vancouver may provide a favourable niche for the survival and spread of $C$. gattii. Global warming also could favour its colonisation into new geographical regions.

The growing number of recent cryptococcosis cases is irrefutable. In this current study, we showed that the $C$. gattii VGII genotype is possibly spreading in several cities of PI and MA (Brazilian Middle-North). More eco-epidemiology studies are necessary for a better understanding of its risk factors, virulence and geoclimatic distribution, as well as its correlation with the outbreak in Vancouver Island and the extent of the expansion of this pathogen in Northeast Brazil. It is likely that the geographical distribution is much wider than currently documented. 


\section{ACKNOWLEDGEMENTS}

To João Batista de Oliveira Silva Júnior, for manuscript's translation into English.

\section{REFERENCES}

Byrnes EJ, Heitman J 2009. Cryptococcus gattii outbreak expands into the northwestern United States with fatal consequences. F1000 Biol Rep 1: 62.

Casali AK, Goulart L, Silva LKR, Ribeiro AM, Amaral AA, Alves SH, Schrank A, Meyer W, Vainstein MH 2003. Molecular typing of clinical and environmental Cryptococcus neoformans isolates in the Brazilian state Rio Grande do Sul. FEMS Yeast Research 3: 405-415.

Cavalcanti MAS 1995. Criptococose e seu agente no Meio-Norte, estados do Piauí e Maranhão, Brasil, PhD Thesis, Universidade Federal do Piauí/Fundação Oswaldo Cruz, Teresina/Rio de Janeiro, $154 \mathrm{pp}$.

Chen S, Sorrell T, Nimmo G, Speed B, Currie B, Ellis D, Marriott D, Pfeiffer T, Parr D, Byth K 2000. Epidemiology and host and varietydependent characteristics of infection due to Cryptococcus neoformans in Australia and New Zealand. Clin Infect Dis 31: 499-508.

DeBess E, Cieslak PR, Marsden-Haug N, Goldoft M, Wohrle R, Free C, Dykstra E, Nett RJ, Chiller T, Lockhart SR, Harris J 2010. Emergence of Cryptococcus gattii-Pacific northwest, 2004-2010. MMWR Morb Mortal Wkly Rep 59: 865-868.

Dixit A, Carroll SF, Qureshi ST 2009. Cryptococcus gattii: an emerging cause of fungal disease in North America. Interdiscip Perspect Infect Dis 2009: 1-13.

Ferrer C, Colom F, Frases S, Mulet E, Abad JL, Alio JL 2001. Detection and identification of fungal pathogens by PCR and by ITS2 and 5.8S ribosomal DNA typing in ocular infections. $J$ Clin Microbiol 39: 2873-2879.

Galanis E, MacDougall L 2010. Epidemiology of Cryptococcus gattii, British Columbia, Canada, 1999-2007. Emerg Infect Dis 16: 251-257.

Hansong MA, Robin CM 2009. Virulence in Cryptococcus species. Adv Appl Microbiol 67: 131-190.

Horta JA, Staats CC, Casali AR, Schrank I, Schrank A, Vainstein MH 2002. Epidemiological aspects of clinical and environmental Cryptcococcus neoformans isolates in the Brazilian state Rio Grande do Sul. Med Mycol 40: 565-571

Huang KY, Huang YC, Hung IJ, Lin TY 2010. Cryptococcosis in nonhuman immunodeficiency virus-infected children. Pediatr Neurol 42: 267-270.

Igreja RP, Lazéra M dos S, Wanke B, Galhardo MC, Kidd SE, Meyer W 2004. Molecular epidemiology of Cryptococcus neoformans isolates from AIDS patients of the Brazilian city, Rio de Janeiro. Medical Mycology 42: 229-238.

Jobbins SE, Hill CJ, D'Souza-Basseal JM, Padula MP, Herbert BR, Krockenberger MB 2010. Immunoproteomic approach to elucidating the pathogenesis of cryptococcosis caused by Cryptococcus gattii. J Proteome Res 9: 3832-3841.

Junior VLP, Galhardo MCG, Lazéra M, Wanke B, Reis RS, Perez M 2006. Criptococose associada à Aids: a importância do cultivo da urina no seu diagnóstico. Rev Soc Bras Med Trop 39: 230-232.

Kidd SE, Hagen F, Tscharke RL, Huynh M, Bartlett KH, Fyfe M, Macdougall L, Boekhout T, Kwon-Chung KJ, Meyer W 2004. A rare genotype of Cryptococcus gattii caused the cryptococcosis outbreak on Vancouver Island (British Columbia, Canada). Proc Natl Acad Sci USA 101: 17258-17263.
Lazera MS, Gutierrez-Galhardo MC, Cavalcanti MAS, Wanke B 2005. Criptococose. In JR Coura (ed.), Dinâmica das doenças infecciosas e parasitárias, vol. II, 1st ed., Guanabara Koogan, Rio de Janeiro, p. 1223-1236.

Martins LMS 2003. Epidemiologia da cryptococcosis em crianças e adultos jovens e diversidade de Cryptococcus neoformans no Meio Norte do Brasil, MSc Thesis, Instituto Oswaldo Cruz-Fiocruz, Rio de Janeiro, 87 pp.

Matsumoto MT, Fusco-Almeida AM, Baeza LC, Melhem MSC, Mendes-Giannini MJS 2007. Genotyping, serotyping and determination of mating-type of Cryptococcus neoformans clinical isolates from São Paulo, state Brazil. Rev Inst Med Trop Sao Paulo 49: 41-47.

Meyer W, Castañeda A, Jackson S, Huynh M, Castañeda E 2003. Molecular typing of Ibero American Cryptococcus neoformans isolates. Emerg Infect Dis 9: 189-195.

Mora DJ, Pedrosa AL, Rodrigues V, Maffei CML, Trilles L, Lazera M dos S, Silva-Vergara ML 2010. Genotype and mating type distribution within clinical Cryptococcus neoformans and Cryptococcus gattii isolates from patients with cryptococcal meningitis in Uberaba, Minas Gerais, Brazil. Med Mycol 48: 561-569.

Nishikawa MM, Lazera MS, Barbosa GG, Trilles L, Balassiano BR, Bezerra CF, Perez MA, Cardareli P, Wanke B 2003. Serotyping of 467 Cryptococcus neoformans isolates from clinical and environmental sources in Brazil: analysis of host and regional patterns. J Clin Microbiol 41: 73-77.

Nucci M, Queiroz-Telles F, Tobón AM, Restrepo A, Colombo AL 2010. Epidemiology of opportunistic fungal infections in Latin America. Clin Infect Dis 51: 561-570.

Pinto Junior VLP, Pone MVP, Pone SM, Campos JMS, Garrido JRP, Barros ACM, Trilles L, Barbosa GG, Morales BP, Bezerra CCF, Lazéra M dos S 2010. Cryptococcus gattii molecular type VGII as agent of meningitis in a healthy child in Rio de Janeiro, Brazil: report of an autochthonous case. Rev Soc Bras Med Trop 43: 746-748.

Santos LO 2000. Criptococose no estado do Amazonas: estudo de 75 casos diagnosticados na Fundação de Medicina Tropical/FMT/ IMTM (1988-1998), Msc Thesis, Instituto Oswaldo Cruz-Fiocruz, Rio de Janeiro, 154 pp.

Santos WRA, Meyer W, Wanke B, Costa SPSE, Trilles L, Nascimento JLM, Medeiros R, Morales BP, Bezerra CCF, Macêdo RCL, Ferreira SO, Barbosa GG, Perez MA, Nishikawa MM, Lazéra MS 2008. Primary endemic Cryptococcosis gattii by molecular type VGII in the state of Pará, Brazil. Mem Inst Oswaldo Cruz 103: 813-818.

Severo CB, Xavier MO, Gazzoni AF, Severo LC 2009. Cryptococcosis in children. Paediatr Respir Rev 10: 166-171.

Sorrell TC 2001. Cryptococcus neoformans variety gattii. Med Mycol 39: $155-168$.

Souza LKH, Souza Junior AH, Costa CR, Faganello J, Vainstein MH, Chagas ALB, Souza ACM, Silva MRR 2009. Molecular typing and antifungal susceptibility of clinical and environmental Cryptococcus neoformans species complex isolates in Goiânia, Brazil. Mycoses 53: 62-67.

Springer DJ, Chaturvedi V 2010. Projecting global occurrence of Cryptococcus gattii. Emerg Infect Dis 16: 14-20.

Trilles L, Lazéra M dos Santos, Wanke B, Thellen B, Boekhout T 2003. Genetic characterization of environmental isolates of the Cryptococcus neoformans species complex from Brazil. Med Mycol 41: 383-390.

Trilles L, Lazéra MS, Wanke B, Oliveira RV, Barbosa GG, Nishikawa MM, Morales BP, Meyer W 2008. Regional pattern of the molecular types of Cryptococcus neoformans and Cryptococcus gattii in Brazil. Mem Inst Oswaldo Cruz 103: 455-462. 